\title{
MASS THROMBUS OF THE LEFT AURICLE
}

\author{
BY \\ WILLIAM EVANS AND ROBERT BENSON
}

From the Cardiac Department of the London Hospital

Received February 12, 1948

We have used the term mass thrombus to describe a clot that forms in the left auricle during life and by reason of its large size or its peculiar location impedes the flow of blood through the mitral orifice. In this paper we examine the clinical and pathological findings in six cases of mass thrombus with the object of discovering a symptom or sign that would simplify the diagnosis.

\section{CASE REPORTS}

Case 1. Female, aged 45. Two months before admission and while in bed she was suddenly seized with a gripping pain across the front of the chest and shoulders; she felt a sense of constriction of the chest with shortness of breath which lasted an hour. Since then she had complained of retrosternal pain on exertion such as walking, and it abated on resting. Besides the pain there was dyspnœa and swelling of the ankles on occasion.

On examination there was slight cyanosis, distension of cervical veins, crepitations over the lung bases, and œdema of the ankles. The pulse was irregular from auricular fibrillation, and the blood pressure was 110/80. The apex beat was displaced to the left, and a mid-diastolic murmur was heard. Response to digitalis was satisfactory, but three weeks after admission to hospital there was sudden severe breathlessness and she died within a few minutes.

At necropsy the right ventricle was slightly hypertrophied and the left auricle moderately dilated. There was severe mitral stenosis, and a spherical and unattached thrombus was found to have lodged in the mitral orifice (Fig. 1). The thrombus measured $3 \mathrm{~cm}$. in diameter, and it had undergone central liquefaction. The other valves were normal. Atheroma of the coronary arteries was slight and insignificant. There was slight atheroma of the pulmonary arteries, and pulmonary embolism was excluded as a cause of sudden death. There was old and recent infarction of the spleen and the left kidney.
Case 2. Female, aged 40. Mitral stenosis had been discovered during pregnancy twelve years before. For ten years she had been short of breath on exertion. Femoral embolism had occurred seven years before, and the following year she began to have pain in the chest. The first attack happened at rest after a day of heavy work; she was suddenly seized with severe retrosternal pain which radiated into the left arm as far as the elbow and lasted until an injection of morphine was given five hours later. Cardiac infarction was suspected, but the electrocardiogram was normal. Since then there had been four similar episodes at rest, the pain lasting up to twenty-four hours on each occasion and requiring morphine. In addition to these unexpected attacks she complained of retrosternal pain which sometimes spread into both arms and came on during exertion; it was relieved instantly by rest. For five years there had been palpitation on occasion as well as shortness of breath, while embolism of the right foot had also occurred. During the past twelve months her general condition had become worse, and four months before she died it had been necessary to admit her into hospital on account of heart failure.

On examination she was short of breath, the neck veins were distended, but there was only slight cyanosis. Enlargement of the liver was accompanied by ascites and much odema of the ankles. The pulse was irregular from auricular fibrillation, and the blood pressure was 190/105. Systolic and mid-diastolic murmurs were heard in the mitral area. Response to digitalis and a mercurial diuretic was unsatisfactory, and her condition gradually deteriorated with increasing dyspnœa. She died suddenly whilst writing a letter.

At necropsy there was moderate hypertrophy of the right ventricle and none of the left ventricle. There was severe mitral stenosis, and the other valves were healthy. The left auricle was moderately dilated, and it contained a slightly adherent thrombus measuring 7 by 6 by $2.5 \mathrm{~cm}$. 


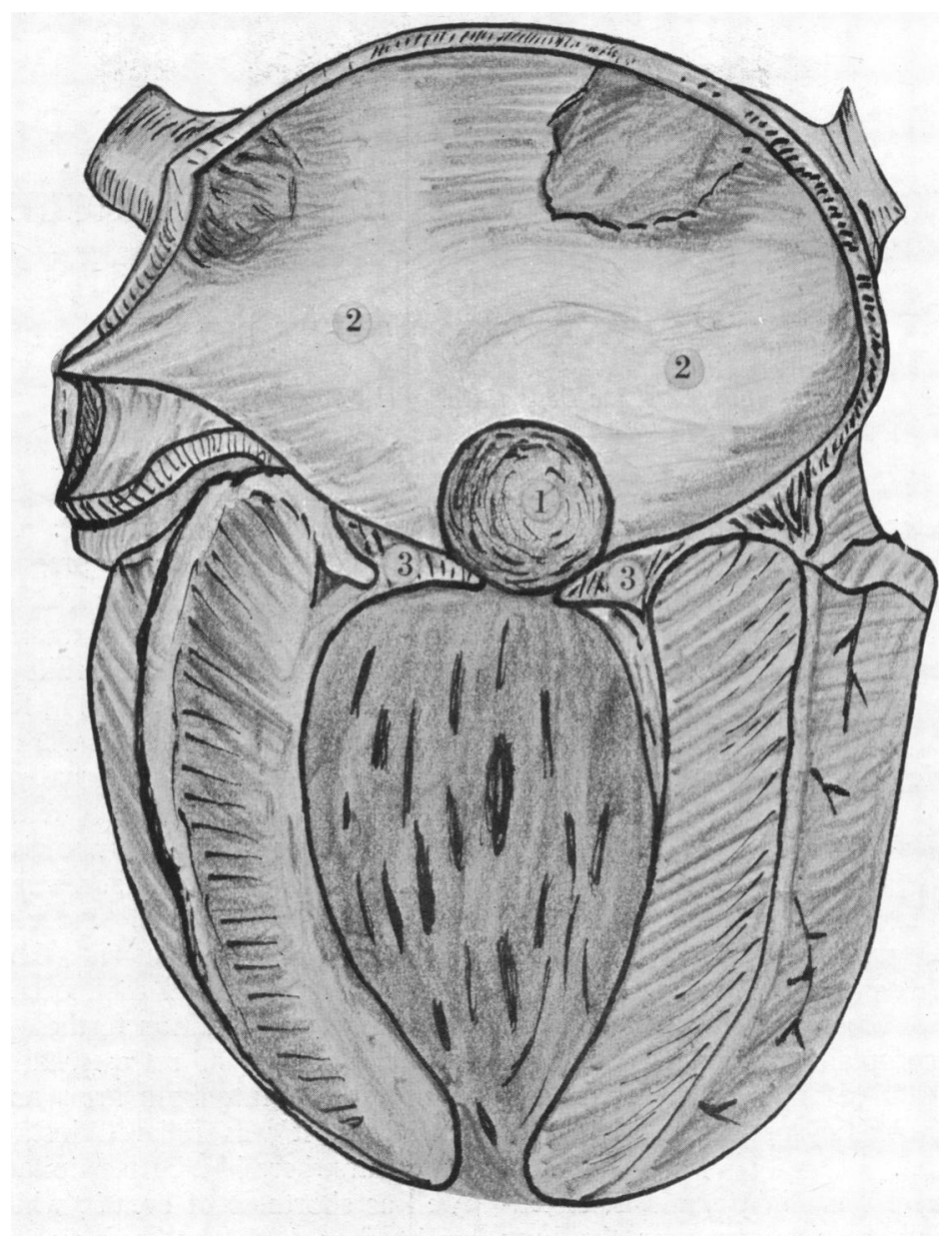

FIG. 1.-Mass thrombus (1) in the left auricle (2) occluding the stenosed mitral orifice (3). From Case 1.

There were ante-mortem clots in both auricular appendages. The coronary arteries were normal, and there was no cardiac infarction. The pulmonary arteries showed moderate atheroma. An old thrombus was found in the abdominal aorta, and there were infarcts in both the spleen and the kidneys.

Case 3. Female, aged 48. For some years she had suffered from attacks of palpitation which would start and stop abruptly, and which were - unaffected by quinidine. For the past nine years she had complained of retrosternal pain on exertion which frequently spread down the left arm and was relieved by resting. Occasionally, however, the pain might start while at rest and might last two days. One such attack had occurred five years before when she was in bed, and she was admitted to hospital where an electrocardiogram showed paroxysmal auricular tachycardia with 2 to $1 \mathrm{~A}-\mathrm{V}$ dissociation. She showed systolic and diastolic murmurs from mitral stenosis. Digitalis changed the rhythm to auricular fibrillation and she remained relatively well for the next four years, though still subject to retrosternal pain on exertion. During the last twelve months of her illness, however, the symptoms of heart failure gradually increased, and ultimately necessitated her admission to hospital.

On examination there was slight cyanosis, dyspnœa, œdema of the back and ankles, and distension of the liver. There were crepitations over the lung bases, and auricular fibrillation was associated with signs of mitral stenosis. The blood pressure was $100 / 70$. On the following day she suddenly became worse with cold and pulseless extremities, and died a few hours later.

At necropsy there was great dilatation of both 


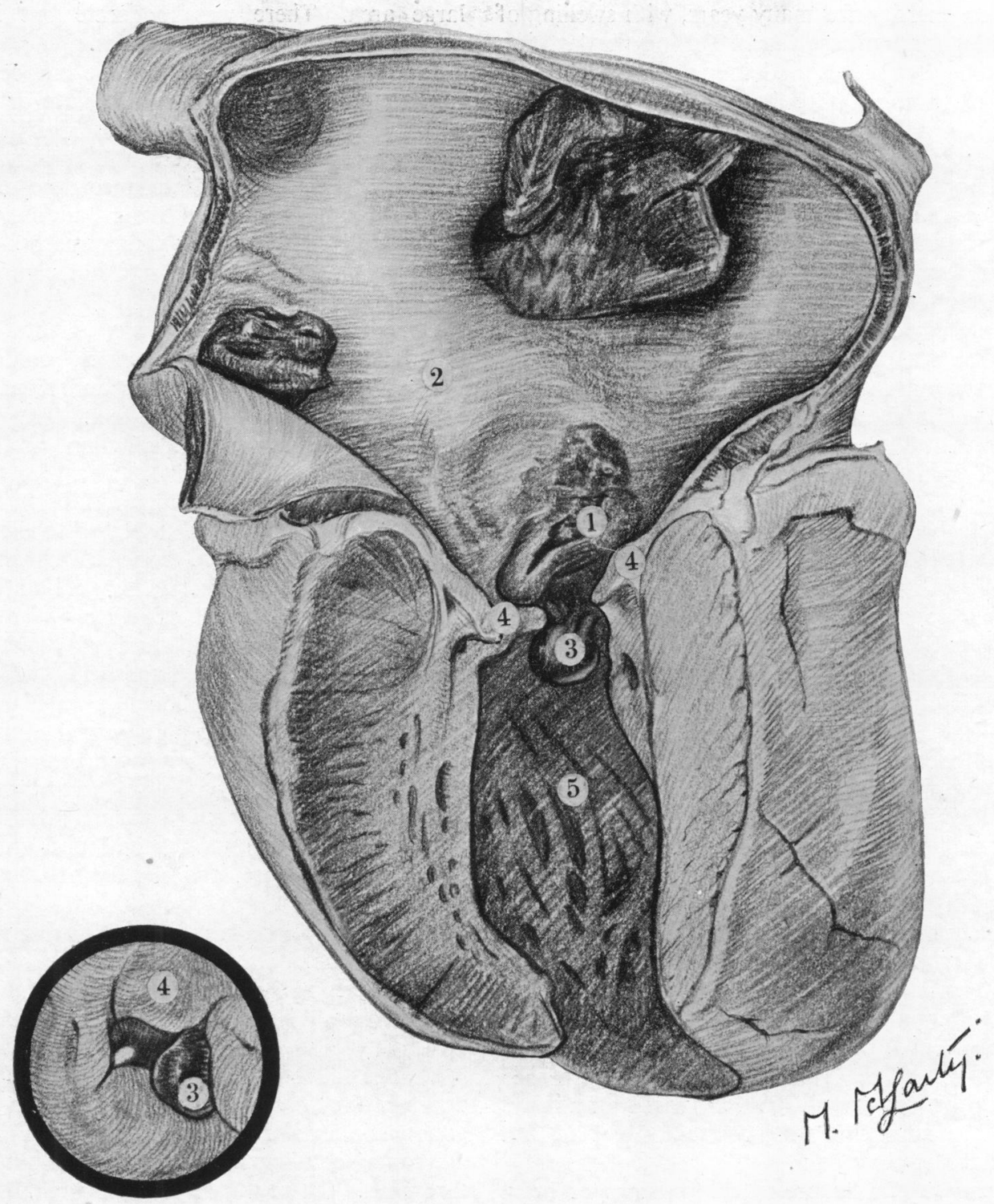

Fig. 2.-Mass thrombus (1) in the left auricle (2) in a patient (Case 3) with mitral stenosis. The lower end of the thrombus (3) projects through the stenosed mitral valve (4) into the left ventricle (5). Lower figure shows the valve from below.

auricles from severe mitral and tricuspid stenosis. The mitral orifice was almost completely occluded by a large thrombus (Fig. 2) measuring 4.6 by 2.0 by $0.8 \mathrm{~cm}$. which was adherent to the auricular aspect of the valve. The lower end of the mass was spherical with a smooth surface and central softening, and projected into the left ventricle. The upper end was flat and lay partly free in the left auricle. A firmly laminated and partly gelatinous thrombus of about the same dimensions was attached to the auricular septum over a small area, and a similar mass lay in the left auricular appendage. The coronary arteries showed only slight atheroma, and there was no evidence of cardiac infarction. The pulmonary arteries were moderately hypertrophied, and showed slight atheroma. Areas of infarction were found in the spleen and the kidneys.

Case 4. Male, aged 31. He had been short of 
breath on exertion for many years, with swelling of the ankles for the past year. During the last two months his symptoms had increased, and shortly before his admission to hospital he had suffered from nocturnal dyspnœa with hæmoptysis on one occasion; the dyspnœa was relieved by sitting up. $\mathrm{He}$ had not specially complained of pain in the chest.

On examination there was moderate dyspnœa with slight cyanosis and œdema, and crepitations were present over the lung bases. The liver was moderately distended, but there was no ascites. The urine contained one-third volume of albumin. The pulse was regular, but auricular fibrillation supervened on the sixth day. The pulse was less readily felt in the right arm. The blood pressure was $155 / 95$. The apex beat was displaced as far as the anterior axillary line, and both systolic and mid-diastolic murmurs were heard in the mitral area. He had an irregular pyrexia from the start and developed a right-sided empyema. He died six weeks after admission.

At necropsy there was great hypertrophy of the right ventricle, and moderate dilatation of the left auricle as the result of severe mitral stenosis. The left auricle contained a large free thrombus with a wavy surface, measuring 8 by 5.5 by $3 \mathrm{~cm}$. In addition there were three smaller thrombi, diameters 0.8 to $1 \mathrm{~cm}$., which were attached to the left auricular wall. The coronary arteries showed very slight atheroma. Old and recent infarcts were found in the lungs, one of which had become purulent, resulting in empyema.

Case 5. Male, aged 39. Breathlessness had been present for many years. Auricular fibrillation with transient aphasia had set in six years before, and shortly afterwards severe heart failure symptoms had supervened. Response to digitalis had been satisfactory and he had remained comparatively well until his symptoms again increased a few days before his admission to hospital. He had not complained of chest pain.

On examination he presented the signs of heart failure with auricular fibrillation. The blood pressure was 140/95. A mid-diastolic murmur was heard in the mitral area. He responded well to treatment by rest in bed, digitalis and a mercurial diuretic, and after seven weeks he was beginning to be allowed out of bed when he suddenly sat up, became extremely cyanosed and died in a few minutes.

At necropsy there was moderate hypertrophy of both ventricles, and great dilatation of the left auricle from severe mitral stenosis. The other valves were normal. A laminated thrombus was found occupying two-thirds of the left auricle, and it was firmly attached to the endocardium over a large area. There was moderate but incidental atheroma of the coronary arteries.

Case 6. Female, aged 41. She had complained of palpitation and shortness of breath for five years and a year later she had heart failure with auricular fibrillation. She improved and remained comparatively well on a maintenance dose of digitalis until a few months before her last admission, when, in spite of treatment, her symptoms had returned with greater severity. She had not complained of pain in the chest.

On examination there was slight dyspnœa, moderate œdema of the ankles, coldness and marked cyanosis of the hands and fingers, and a blotchy discolouration of the feet. The pulse was irregular from auricular fibrillation, and was less easily felt on the right side. The blood pressure was 170/120 in the right arm, and 270/120 in the left arm. The apex beat was displaced to the left, and loud systolic and mid-diastolic murmurs were heard in the mitral area. A few crepitations were heard at both lung bases. The liver was moderately enlarged. There was bilateral papillœedema with retinal hæmorrhages; and the urine, which had a low specific gravity, contained a large amount of albumin. Digitalis and a mercurial diuretic were given but there was no improvement. During the fourth week cerebral embolism occurred, followed by hæmaturia, oliguria, increasing drowsiness and Cheyne-Stokes respiration; the blood urea rose to $210 \mathrm{mg}$. per $100 \mathrm{ml}$. and she died six weeks after admission.

At necropsy there was slight and moderate hypertrophy of the right and left ventricle respectively. Both auricles were moderately dilated, and there was severe mitral stenosis. The other valves were healthy. On opening the left auricle a spherical thrombus fell out; the clot was quite unattached and measured $4 \mathrm{~cm}$. in diameter, and it had undergone cystic degeneration. The left auricular appendage contained a few small fragments of ante-mortem thrombus. There was slight incidental atheroma of the coronary arteries. The right subclavian artery contained an old embolus, and infarction was present in the brain, the spleen and the kidneys. Histological examination of the kidneys showed acute focal interstitial nephritis.

\section{DEFINITION}

The term " ball thrombus" was used by Wood (1814) who described for it the following criteria: absence of attachment to the auricular wall, a diameter exceeding that of the passage immediately ahead of it, and a consistency that does not allow it to lodge in that passage. Abramson (1924) in a review accepted the original definition, but 
mentioned the case of Bozzolo (1896) in which a large pedunculated thrombus was found at necropsy. Hewitt (1916) stipulated that the thrombus should have a smooth surface which shows no evidence of previous attachment to the heart wall; while Potter (1926) pointed out that the smoothness of the surface depends on the time the thrombus has been free, and accepted Wood's original definition. Elson (1934), Aronstein and Neumann (1939), and Garvin (1941) considered that a distinction between free and pedunculated thrombi was academic since each produced identical symptoms. To avoid ambiguity over the terminology of ball thrombus we have used the term mass thrombus to include any large thrombus, free or attached, that occupies the greater part of the left auricle, as well as any smaller thrombus that by reason of its proximity to the mitral valve may cause obstruction to the flow of blood through the mitral orifice. When thrombosis is limited to the left auricular appendage it is without clinical significance except as a source of embolism.

\section{INCIDENCE}

Since Wood's original case in 1814 the reported cases have been well reviewed by Welch (1899), Hewitt (1916), Abramson (1924), Aronstein and Neumann (1939), Wright et al. (1944). Forty-six cases have hitherto been recorded. Cleland (1936) found only one ball thrombus among 3000 necropsies, and Garvin (1941) three among 6285 which included 156 cases with rheumatic heart disease. Ball thrombus in chambers other than the left auricle is very rare (Gairdner, 1893; French, 1912; Wright et al., 1944). Our paper includes an analysis of 3083 consecutive necropsies among which there were 46 cases of mitral stenosis; in 6 of the latter a mass thrombus was discovered in the left auricle, and 3 of them conformed to the more rigid, and in our view too limited, definition of ball thrombus.

\section{ATIOLOGY}

Ziemssen (1890) was the first to state that mitral stenosis was essential to the formation of a ball thrombus; in the majority of cases there is great narrowing of the valve. Yet a few cases have been recorded in which mitral stenosis was absent (Voelcker, 1893; Fischer, 1901; Pawinski, 1909; Dressler, 1928; Schwarz and Biloon, 1931; Kaplan and Hollingsworth, 1935). It is generally held that established auricular fibrillation contributes to the formation of a mass thrombus and that the condition rarely develops with normal rhythm (Osler, 1890; Spain, 1943). In one of our cases fibrillation had been paroxysmal until not more than four months before death, whilst in another fibrillation developed only at the last. The size of the left auricle has no direct bearing on the formation of a mass thrombus, and there was only moderate dilatation in four of our cases. In two there was great dilatation, but in none was it aneurysmal. It is of interest that in the two cases of aneurysmal dilatation of the left auricle found in this series there was only moderate stenosis of the mitral valve.

\section{SyMPTOMATOLOGY}

It is probable that some of the symptoms and signs that have been ascribed to ball thrombus were the direct outcome of severe mitral stenosis; they include dyspnœa and embolism. In order to evaluate the effects of the mass itself in the left auricle the symptoms ascribed to ball thrombus were compared with those arising from tumour of the left auricle (Table I). Twenty-seven reported cases were studied, and they included 21 with myxoma, 5 with sarcoma, and 1 with fibroma.

\section{TABLE I}

Symptoms, other than Pain, in Patients Reported to have Tumour or Mass Thrombus OF THE LeFT Auricle. Figures Denote the Number of CASES

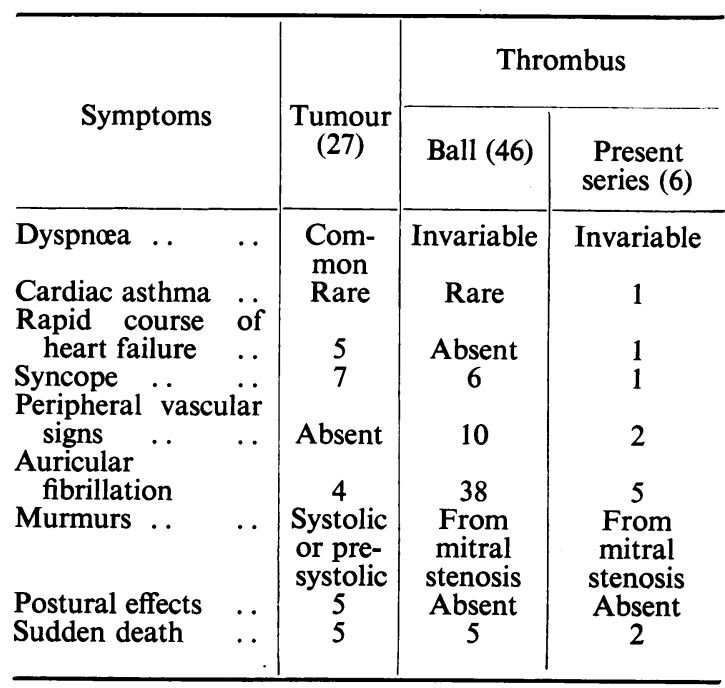

Dyspncea was a more prominent symptom in the cases of ball thrombus as might be expected from the associated mitral stenosis. It usually showed no special features, although cardiac asthma has been described (Schwarz and Biloon, 1931; Aronstein and Neumann, 1939). Such dyspnœa in uncomplicated mitral stenosis is thought to be due to rapid increase in the heart rate (McGinn and White, 1934); Ernstene (1936) and Bramwell and Jones (1944) consider that occlusion of the mitral orifice 
is also a factor. Although dyspnœa was rather less common as the first symptom of tumour of the left auricle, it occasionally presented unusual features in that it was sometimes severe in the absence of œdema (Horneffer and Gautier, 1913), or noticeably relieved by sitting up (Gilchrist and Millar, 1936). In Ernstene's (1936) case of mass thrombus due to bacterial endocarditis the patient lost consciousness whenever he sat up during an attack of paroxysmal dyspnœa. In our series the first attack of chest pain was associated with severe dyspnœa in Case 1 and in Case 4 paroxysmal dyspnœa, which was relieved by assuming the upright posture, was a prominent symptom.

Heart failure is common to cases of both tumour and thrombus, although in the former it is more rapid in its progress from the time of onset of symptoms (Houck and Bennet, 1929; Ludwig, 1933; Jensen, 1934; Shelburne, 1935a, 1935b; Gilchrist and Millar, 1936). In our series the symptoms of failure made their appearance from two months (Cases 1 and 4) to eleven years (Case 2) before death, and the average duration was four years. The degree of failure shortly before death was slight in Cases 1,3, and 5, moderate in Case 6, and severe in Cases 2 and 4 . Failure was rapidly progressive whilst in normal rhythm in Case 4, though fibrillation supervened at the last.

Giddiness and syncope, admittedly common symptoms in cardiological practice, appear to be more frequent in both tumour and mass thrombus of the left auricle. Such symptoms were present in six reported cases of ball thrombus (Wood, 1814; Osler, 1897; Mathewson and Rotherford, 1920; Schwarz and Biloon, 1931; Elson, 1934; Garvin, 1941), and in our Cases 1 and 2. Ernstene and Lawrence (1936) described a patient who preferred to lie flat during attacks of paroxysmal dyspnea because sitting up promptly resulted in loss of consciousness. Giddiness and syncope are also common symptoms in tumour of the left auricle and they were present in seven reported cases (Berthenson, 1893; Horneffer and Gautier, 1913; Houck and Bennet, 1929; Ludwig, 1933; Gilchrist and Millar, 1936; Shelburne, 1935a; Fawcett and Ward, 1939). In Houck and Bennet's case, recurrent fainting in the erect posture was the first and most prominent symptom, and it was followed a few weeks later by sudden death. In Shelburne's case fainting was followed in a few days by severe heart failure. Paroxysmal fibrillation lasting three minutes was noticed during a fainting attack in Fawcett's case. In our series loss of consciousness was found only once (Case 3), and even in this case it was probably the outcome of paroxysmal tachycardia.

Auricular fibrillation is naturally a common accompaniment of mass thrombus since both conditions are found in long-standing mitral stenosis. Normal rhythm has sometimes been noted (Osler, 1890; Spain, 1943), and it was observed in two of our patients; in Case 2 paroxysmal fibrillation was present for some years, while in Case 4 fibrillation set in very late. That arrhythmia can result from a mass in the left auricle, quite apart from valvular disease, is shown by the incidence of paroxysmal or established fibrillation in cases of mass thrombus in the absence of mitral disease (Dressler, 1928; Kaplan and Hollingsworth, 1935; Pawinski, 1909), and in tumour of the left auricle (Jensen, 1934; Fawcett and Ward, 1939). In other cases of tumour, bouts of extrasystoles or paroxysmal tachycardia have been noted (Eimer, 1928; Gilchrist and Millar, 1936; Thompson, 1944), and failure was present in at least two cases at the time. In only one case did electrocardiographic evidence assist in the diagnosis (Shelburne, 1935a) when partial heart block developed due to sarcomatous involvement of the conduction system.

Peripheral vascular phenomena. Fishberg (1940) stated that occlusion of the mitral orifice by a free or pedunculated thrombus can only be assumed with any probability in the rare instances in which intense cyanosis develops with symmetrical ischæmia of all the extremities, the tip of the nose, and the ears. $\mathrm{He}$ added that even this clinical picture may be caused by a very tight mitral stenosis. The mechanism of this symmetrical ischæmia, which may proceed to gangrene, is thought to be severe peripheral vasoconstriction following a serious fall in the cardiac output. Such a clinical picture developed in varying degrees in 10 of the 46 reported cases of ball thrombus (Fischer, 1901; Covey et al., 1928; Schwarz and Biloon, 1931; Elson, 1934; Schiller, 1935; Ernstene and Lawrence, 1936; Spain, 1934; Aubertin and Rimé, 1926). Gangrene of the tip of the nose was described by Lutembacher (1917) but it is probable that this was embolic since bacterial endocarditis was also present. Purpura was also a feature in two cases.

In our series non-embolic peripheral vascular manifestations were present in two cases. In Case 3 the extremities suddenly turned cold and pulseless, and at necropsy the mitral orifice was found occluded. In Case 6 extreme cyanosis of the fingers was observed, disproportionate to the degree of heart failure, and at necropsy a loose ball thrombus was found in the left auricle. No case of transient peripheral cyanosis or gangrene was seen. Among the 27 cases of tumour of the left auricle only two presented undue cyanosis of the hands and face, and severe heart failure was present in both. It appears likely, therefore, that a stenosed mitral 
valve is at least as important as a co-existent mass thrombus in the production of these phenomena. Embolism is naturally common because of the mitral stenosis in cases of mass thrombus, but it is less frequent in those with tumour of the left auricle.

Murmurs. Evaluation of reported auscultatory signs is notoriously difficult, especially so with early writers. It would appear, however, that a ball thrombus has little influence on the murmurs produced by the stenosed mitral valve. Changing murmurs, although stressed in the past (Battistini, 1909; Pawinski, 1909) are rarely observed. The case of Covey et al. (1928) was remarkable in that a presystolic murmur developed whilst the patient was in hospital, and finally became so loud as to be heard a few feet away. Schwartz and Biloon (1931) and Schiller (1935) noted the disappearance of sounds and murmurs with the advent of severe symmetrical cyanosis due to occlusion of a stenosed mitral valve by a mass thrombus, while Garvin (1941) remarked on the absence of murmurs in two cases of severe mitral stenosis with ball thrombus formation. That a mass in the left auricle can cause murmurs which are indistinguishable by ordinary methods from those of mitral stenosis was the opinion of Ludwig (1933) who collected 20 reported cases and added another. It has also been stated that a tumour of the left auricle may cause severe symptoms without the production of murmurs (Shelburne, 1935; Bennett et al.; 1938; Fawcett and Ward, 1939; Hamilton-Paterson and Castleden, 1942). Of the murmurs found in cases of tumour of the left auricle a systolic murmur was the usual one, although a presystolic murmur was sometimes present.

Radiology. Mass thrombus in the left auricle cannot be detected by cardioscopy except in those very rare cases where a mural thrombus has become calcified (Berk, 1939). It does not affect the size or shape of the heart. Tumours of the left auricle may alter the outline of the heart to resemble closely that of mitral stenosis (Dressler, 1928; Ludwig, 1933; Gilchrist and Millar, 1936; Bennett et al. 1939), adding to the already erroneous diagnosis based on the murmurs which may be present. - Tumour of the right auricle may sometimes be suspected by a cardioscopic appearance similar to that seen in primary pulmonary hypertension (Hamilton-Paterson and Castleden, 1942), but a cardiogram should prevent this error.

Sudden death. Garvin (1941) described a man in whom heart failure had responded well to treatment in hospital, but who died suddenly when leaving the ward; at necropsy a small pedunculated thrombus was found to be wedged in the mitral orifice.
Sudden death may also result from a mass which occupies the larger part of the left auricle, and this has been reported in several instances where necropsy showed a tumour almost filling the auricle (Hoffmann, 1921; Houck and Bennet, 1929; Jensen, 1934; Gilchrist and Millar, 1936; Thompson, 1944). In our series death occurred unexpectedly and within a few minutes in Cases 1 and 5; in the former there was occlusion of the mitral orifice by the thrombus, and in the latter the thrombus filled two-thirds of the left auricle. In Case 3 death occurred within a few hours of the onset of peripheral ischæmia, and at necropsy the mitral office was almost completely occluded by a thrombus. As in the case of Thompson (1944) the terminal event was pulmonary œdema, presumably due to sudden heart failure, although in our case pulmonary œdema was remarkably slight.

Cardiac pain. An accurate account of pain was unusual in the literature that was reviewed, and vague terms such as oppression, præcordial pain, thoracic pain, etc., were used in the reported cases of ball thrombus (Arnold, 1890; Bozzolo, 1896; Hay, 1900; Ott, 1901; Elson, 1934) and in tumour of the left auricle (Bamberger, 1872; Berthenson, 1893; Thompson, 1904; . Fawcett and Ward, 1939). Retrosternal pain was described in two cases of myxoma by Gilchrist and Millar (1936) and Bennett et al. (1938), and in one of the three cases of occluding thrombus reported by Schwartz and Biloon (1931). The pain of cardiac ischæmia was a noticeable symptom in three of our six cases of mass thrombus in the left auricle. Having regard to the non-specificity of other signs in this condition we mean to emphasize the importance of this symptom. As we are at present observing 20 patients with mitral stenosis and cardiac pain, some of them for as long as ten years, it is unlikely that the pain is invariably caused by a mass thrombus. None the less, in only one of the four cases in our series of 46 consecutive deaths from mitral stenosis in which pain had been a feature during life was a mass thrombus absent from the left auricle at necropsy. Again, in six cases in which a mass thrombus was found, three had complained of cardiac pain, while only one of the remaining 40 cases of mitral stenosis without a mass thrombus of the left auricle had suffered from cardiac pain (Table II). We bring evidence to show, therefore, that although sometimes present in uncomplicated mitral stenosis, cardiac pain is a more likely event when mass thrombus in the left auricle has been added. The pain in our cases was indistinguishable from that of cardiac ischæmia due to coronary disease or cardiac infarction. Thus, its site was retrosternal, and its spread was into the shoulders 
TABLE II

The Relation of Cardiac Pain to Mass Thrombus of the Left AURICle from an ANALYSIS OF 46 Consecutive Cases of Mitral Stenosis Examined AT NECROPSY

\begin{tabular}{|c|c|c|c|c|}
\hline Cases & $\begin{array}{c}\text { Pain of } \\
\text { cardiac } \\
\text { ischæmia }\end{array}$ & $\begin{array}{c}\text { Grade of } \\
\text { mitral } \\
\text { stenosis }\end{array}$ & $\begin{array}{l}\text { Coronary } \\
\text { atheroma }\end{array}$ & $\begin{array}{l}\text { Mass } \\
\text { throm- } \\
\text { bus in } \\
\text { left } \\
\text { auricle }\end{array}$ \\
\hline $\begin{array}{l}1 \\
2 \\
3 \\
4\end{array}$ & $\begin{array}{l}\text { Present } \\
\text { Present } \\
\text { Present } \\
\text { Present }\end{array}$ & $\begin{array}{l}\text { Severe } \\
\text { Severe } \\
\text { Severe } \\
\text { Severe }\end{array}$ & $\begin{array}{c}\text { Incidental } \\
\text { None } \\
\text { Incidental } \\
\text { None }\end{array}$ & $\begin{array}{l}\text { Present } \\
\text { Present } \\
\text { Present } \\
\text { Absent }\end{array}$ \\
\hline $\begin{array}{l}5 \\
6 \\
7\end{array}$ & $\begin{array}{l}\text { Absent } \\
\text { Absent } \\
\text { Absent }\end{array}$ & $\begin{array}{l}\text { Severe } \\
\text { Severe } \\
\text { Severe }\end{array}$ & $\begin{array}{l}\text { Incidental } \\
\text { Incidental } \\
\text { Incidental }\end{array}$ & $\begin{array}{l}\text { Present } \\
\text { Present } \\
\text { Present }\end{array}$ \\
\hline $\begin{array}{l}8 \\
\text { to } \\
46\end{array}$ & Absent & $\begin{array}{lc}\text { Slight: } & 5 \\
\text { Moderate: } & 17 \\
\text { Severe: } & 17\end{array}$ & $\begin{array}{lc}\text { None: } & 0 \\
\text { Incidental: } & 35 \\
\text { Severe: } & 4\end{array}$ & Absent \\
\hline
\end{tabular}

and sometimes down one or both arms. It was brought on by exertion, especially walking, and it ceased as soon as the exercise which caused it was discontinued. In Cases 1, 2, and 3 the pain also occurred at rest. In Case 1 the first attack set in during rest and lasted an hour; it was accompanied by breathlessness. In Case 2 the initial attack came on at rest and was only relieved five hours later after an injection of morphine; on five other occasions the painful attacks in this patient lasted for many hours. Although the pain in Case 3 had usually been caused by exertion, her most severe attack startled her during rest and she cried out as she lost consciousness; auricular tachycardia was present in this attack; subsequently when in slow auricular fibrillation, she experienced cardiac pain. In these three cases where the pain occurred at rest it was always more readily brought on by exertion. Levine (1922) found only one case of mitral stenosis among 103 cases of angina, and White (1936) found two among 500. More recently Levine and Kauver (1942) found cardiac pain in 5 per cent of 314 patients with mitral stenosis. In our series of 46 patients with mitral stenosis at necropsy cardiac pain had been present in four; in a fifth patient the attacks of retrosternal pain were brought on solely by paroxysmal tachycardia, and were not related to effort.

Angina from all causes is reported as three times commoner in men than in women, but naturally the higher incidence of mitral stenosis in women increases the incidence in them of cardiac pain when it is the outcome of mitral stenosis, and all our cases were women.
Concerning the age incidence of cardiac pain in mitral stenosis White and Mudd (1927) found that only about 2 per cent of cases of angina from all causes developed the pain before 40 , while Levine and Kauver (1942) found 8 per cent in their series of mitral stenosis. Three of our four cases began to have pain before 40 . The average age at death in our series was 38 years, an age much younger than that given by Eppinger and Levine (1934) for all women with angina, or by Levine and Kauver (1942) in angina and mitral stenosis, where it was about 60 years.

Different mechanisms have been invoked to explain the occurrence of cardiac pain in these cases (Sternberg, 1923; Telia, 1925; Hochrein, 1930; Blackford, 1940). The importance of marked pulmonary changes with severe cyanosis was reported by Burgess and Ellis (1942) and by Parker and Weiss (1936), but they were not present in any of our cases.

Naturally, coronary atheroma might coincide with mitral stenosis, but in our cases it was a casual finding when present, and it was never prominent enough to be significant as a cause of cardiac ischæmia.

That cardiac pain is rare in auricular fibrillation has been over-emphasized, for although Levine (1922) found them to be associated in but two of 103 cases of angina, we have often observed them together even in non-valvular heart disease, while in three of the present cases cardiac pain and auricular fibrillation were found side by side. Although some degree of heart failure was a common finding, we did not think that it contributed in any way to the development of pain.

We believe that cardiac pain in mitral stenosis is the result of an impoverished coronary circulation resulting from the stenotic valvular effect; when mass thrombus in the left auricle is added the susceptibility to cardiac ischæmia is increased. The fact that the incidence of cardiac pain is higher in those cases of mitral stenosis complicated by mass thrombus in the left auricle gives support to the belief that the pain is caused by cardiac ischæmia.

\section{Summary and ConClusions}

The clinical findings in reported cases with ball thrombus or myxoma of the left auricle have been examined with the object of deciding which symptoms or signs permit a diagnosis of ball thrombus during life: Among those attributed to the condition were dyspnœa, heart failure, giddiness, syncope, auricular fibrillation, certain heart murmurs, embolism and extreme cyanosis, 
ischæmia or gangrene of the extremities. None of them was a consistent finding.

We consider that the definition customary for ball thrombus is too exacting and we suggest that the term mass thrombus should take its place and should include any large thrombus, free or attached, that occupies the greater part of the left auricle, as well as any smaller thrombus that by reason of its nearness to the mitral valve may cause obstruction to the flow of blood through the mitral orifice.

Among 46 consecutive cases of pure mitral stenosis examined at necropsy we found six in which a mass thrombus was present in the left auricle. Cardiac pain was a noticeable symptom during life in three instances, and it occurred once only among the 40 cases without a mass thrombus.

We conclude that although cardiac pain from cardiac ischæmia may occur in uncomplicated mitral stenosis, the symptom is more likely to arise when a mass thrombus has formed in the left auricle.

We wish to thank Professor Dorothy Russell, Director of the Bernhard Baron Institute of Pathology, and Dr. W. W. Woods, for the records of the findings at necropsy in the cases we describe, and Dr. A. E. Clark-Kennedy and Dr. Horace Evans for permission to publish two cases under their care. We are grateful to Sir John Parkinson, Physician to the Cardiac Department, for his helpful criticism of this paper.

\section{REFERENCES}

Abramson, J. L. (1924). Ann. Clin. Med., 3, 327.

Arnold, J. (1890). Beitr. path. Anat., 8, 29.

Aronstein, C. G., and Neuman, L. (1939). Arch. Pathol., 27, 907 .

Aubertin, C., and Rimé, G. (1926). Presse méd., 4, 736.

Bamberger, V. (1872). Wien. med. Wschr., 22, 26.

Battistini, F. (1909). G. Accad. Med. Torina, 15, 313.

Bennett, D. W., Konigsberg, J., and Dublin, W. (1938). Amer. Heart J., 16, 117.

Berk, L. H. (1939). Arch. intern. Med., 63, 1183.

Berthenson, L. (1893). Arch. Méd. exp., 5, 386.

Blackford, L. M. (1940). Amer. Heart J., 20, 492.

Bozzolo, C. (1896). Rif. med., 1, 98, 328.

Bramwell, C., and Jones, A. M. (1944). Brit. Heart J., 6, 129.

Burgess, A. M., and Ellis, L. B. (1942). New Engl. J. Med., 226, 937.

Cleland, J. B. (1936). Med. J. Austral., 2, 50.

Covey, G. W., Crook, R., and Rogers, F. H. (1928). Amer. J. med. Sci., 175, 60.

Dressler, W. (1928). Wien. klin. Wschr., 41, 1245.

Eimer, K. (1928). Dtsch. Arch. klin. Med., 159, 164.

Elson, J. (1934). Amer. Heart J., 10, 120.

Eppinger, E. G., and Levine, S. A. (1934). Arch. intern. Med., 53, 120.

Ernstene, A. C., and Lawrence, J. C. (1936). Amer. Heart J., 12, 618.

Fawcett, R. E. M., and Ward, E. M. (1939). Brit. Heart J., 1, 249.

Fischer, K. (1901). Ann. allg. Krankenh. München, 11, 165-184.

Fishberg, A. (1940). Heart Failure. Lea and Febiger, Philadelphia, p. 521.

French, H. (1912). Guy's Hosp. Rep., 66, 353.

Gairdner, W. T. (1893). Edinb. Hosp. Rep., 1, 221.

Garvin, C. F. (1941). Amer. Heart J., 21, 371.

Gilchrist, A. R., and Millar, W. G. (1936). Edin. med. $J ., 43,243$.

Hamilton-Paterson, J. L., and Castleden, L. I. M. (1942). Brit. Heart J., 4, 103.

Hay, J. (1900). L'pool. med-chir. J., 20, 135.

Hewitt, J. H. (1916). Johns Hopk. Hosp. Rep., 17, 1.

Hochrein, M. (1940). Dtsch. Arch. klin. Med., 169, 195.

Hoffmann, P. D. (1921). Proc. N.Y. path. Soc., 21, 85 .

F*
Horneffer, C., and Gautier, P. (1913). Rev. med. Suisse rom., 33, 57.

Houck, G. H., and Bennet, G. A. (1929-30). Amer. Heart J., 5, 787.

Jensen, C. R. (1934). Northw. Med., Seattle, 33, 394.

Kaplan, D., and Hollingsworth, E. W. (1935). J. Amer. med. Ass., 105, 1264.

Levine, S. A. (1922). Ibid., 79, 928.

-, and Kauver, A. J. (1942). J. Mt. Sinai Hosp., N.Y., 8, 754 .

Ludwig, H. (1933). Zeitsch. klin. Med., 123, 587.

Lutembacher, R. (1917). Arch. Mal. Cour, 10, 353.

Mathewson, G. D., and Rotherford, A. (1920). Lancet, 745.

McGinn, S., and White, P. D. (1934). Amer. Heart J., 9, 697.

Ogle, J. W. (1863). Trans. path. Soc. Lond., 14, 127.

Osler, W. (1890). Johns Hopk. Hosp. Rep., 2, 56. (1897). Montreal med. J., 25, 729.

Ott, F. (1901). Ann. d. stadt. allg. Krankenh. z. München, 11, 185.

Parker, F., and Weiss, S. (1936). Amer. J. Path., 12, 573.

Pawinski, J. (1909). Z. klin. Med., 68, 75.

Potter, E. B. (1926). Ann. clin. Med., 4, 736.

Schiller, I. A. (1935). J. Mt. Sinai Hosp., N.Y., 2, 153.

Shelburne, S. A. (1935a). Ann. intern. Med., 9, 340.

- $(1935 b)$. Texas State J. Med., 31, 433 .

Schwartz, S. P., and Biloon, S. (1931). Amer. Heart J., 7,84.

Spain, D. M. (1943). Ann. intern. Med., 19, 144.

Sternberg, M. (1923). Z. klin. Med., 97, 110.

Telia, L. (1925). Arch. Mal Cour, 18, 531.

Thompson, R. B. (1944). Brit. Heart J., 6, 23.

Voelcker, A. F. (1893). Trans. path. Soc. Lond., 44, 31.

Welch, W. (1899). "Thrombosis." In: Albutt, F. C., System of Medicine, London, 6, 720.

White, P. D., and Mudd, S. G. (1927). Amer. Heart J., 3,1 .

(1936). Diseases of the Coronary Arteries and Cardiac Pain, N.Y., p. 269.

Wood, W. (1814). Edin. med. surg. J., 10, 50.

Wright, I. S., Flynn, J. E., and Druet, K. L. (1944). Amer. Heart J., 27, 858.

Ziemssen, V. (1890). Verh. Kongr. inn. Med., 9, 281. 